\title{
The validation of a workplace incivility scale within the South African banking industry
}

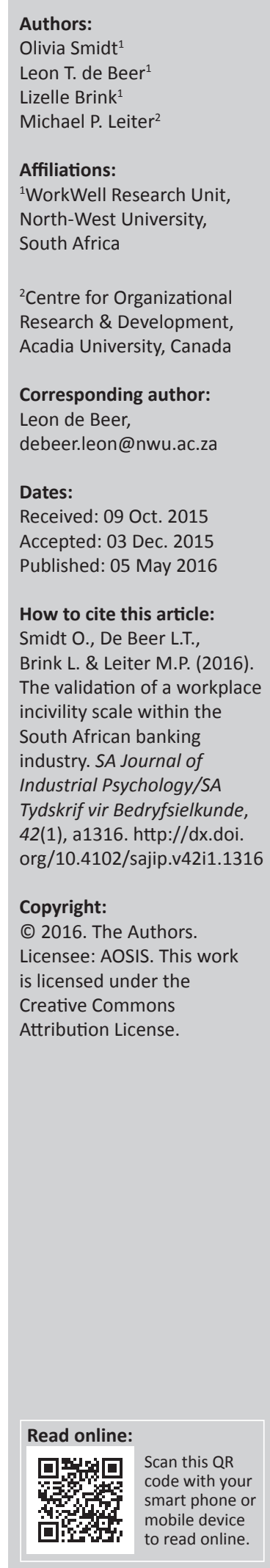

Orientation: Workplace incivility holds consequences for both individuals and organisations. Managers are becoming increasingly aware of this phenomenon. Currently, there is no workplace incivility scale validated for use within the South African context.

Research purpose: To investigate the reliability and validity of the adapted workplace incivility scale by Leiter and colleagues for use within South Africa.

Motivation for the study: As it is currently difficult to measure workplace incivility within the South African context because of the lack of a valid and reliable scale, it is necessary to validate such a scale.

Research design, approach and method: A cross-sectional research approach was used for the study. Convenience sampling $(N=345)$ was used within the South African banking industry. Specifically, the factor structure, convergent validity, discriminant validity and predictive validity were investigated in order to establish the overall validity of the scale.

Main findings: The results confirmed that the scale showed a three-factor structure as bestfitting with acceptable reliability coefficients. Furthermore, discriminant validity could be shown between workplace incivility and workplace bullying, that is, supporting that these two constructs are not the same phenomenon. In terms of relationships, colleague incivility did not significantly predict any of the outcome variables and instigated incivility only being a negative predictor of job satisfaction and a borderline statistically significant negative predictor of work engagement. However, supervisor incivility predicted all the outcomes negatively.

Practical/Managerial implications: Based on the results, workplace incivility should be addressed because of the harmful effects it can have, not only on employees but also on organisations. It is therefore necessary for managers to create awareness of workplace incivility in order to ensure that it does not integrate within the organisational culture and affect individual and organisational performance.

Contribution/Value-add: The study contributes to the limited research available in South Africa regarding workplace incivility by providing a scale that is valid and reliable.

\section{Introduction}

Deviant behaviour within the workplace has received increased attention in recent years (Lim, Cortina \& Magley, 2008), of which workplace bullying is one of the most well-known problems. Einarsen and Skogstad (1996) explain workplace bullying as systematic, repeated, persistent and continuous negative acts in which the victims present with an inferiority to defend themselves in the actual situation - and that single negative acts are not considered bullying. However, even though ample research has been conducted in terms of more overt forms of workplace deviance (Hershcovis, 2010), there are still areas that remain unexplored. For example, a milder form of workplace deviance referred to as workplace incivility has not commanded any attention in South Africa. In contrast to workplace bullying, workplace incivility can be described as acts that are of lower intensity and frequency - either verbal or non-verbal (Andersson \& Pearson, 1999). Additionally, for behaviour to be classified as uncivil, the intention of the instigator to harm the victim is required to be perceived as ambiguous, that is, no clear intention to harm is perceived (Andersson \& Pearson, 1999). According to Cortina, Magley, Williams and Langhout (2001), when the instigator has the intention to harm another individual, it indicates psychological aggression; thus, it strictly cannot be considered to be merely uncivil. Actions that can be interpreted as rude, sarcastic or other perceived impolite behaviour are all examples of uncivil behaviours, which can be experienced within the work environment (Tarraf, 2012). 
Workplace incivility and workplace bullying are both classified as deviant work behaviours. There is often confusion as to how workplace bullying differs from workplace incivility, especially as incivility can be mistaken for bullying (Branch, 2008). Specifically, workplace incivility differs from workplace bullying in that bullying occurs when a person is exposed to negative behaviour from other employees over an extended period of time (Einarsen, 2000). These purposeful acts may include abuse that is frequent; teasing, mockery and purposeful exclusion from social situations. Bullying is therefore more intense because of its intent, intensity and frequency (Hershcovis, 2010). Furthermore, workplace bullying is considered to be highly persistent and indicates a clear power imbalance between two or more parties, whereas workplace incivility is behaviour of a low intensity, intention remains ambiguous and power imbalance is not a prerequisite (Hershcovis, 2010). Workplace incivility is not in violation of any specific laws (Lim \& Cortina, 2005), and this may be a reason why managers focus less on workplace incivility in comparison with other forms of aggressive behaviours that are more obvious (Lim et al., 2008). By way of explanation, managers do not realise the consequences of such behaviour in their departments, especially as this kind of behaviour is more subtle than workplace bullying and outright harassment (Lim et al., 2008).

Concerning the prevalence of workplace incivility, a study of 800 employees within the United States of America revealed that $10 \%$ of employees have witnessed or experienced uncivil work behaviours every working day, and $20 \%$ of these employees were the victims of uncivil behaviour with a frequency of one working day per week (Pearson \& Porath, 2005). Another study by the authors in Canada yielded the following statistics: $25 \%$ of the employees witnessed uncivil behaviour on a daily basis and $50 \%$ of the employees reported to being direct victims of such behaviour, also with a frequency of once per week (Pearson \& Porath, 2005).

Even though the intensity and frequency of workplace incivility is low, the consequences of workplace incivility are not. Some implications of workplace incivility for the individual may include experiences related to anxiety, depression and in severe instances even suicide ideation (Estes \& Wang, 2008). Moreover, research shows that workplace incivility may even cause individuals to experience physical illness such as migraines, ulcers and heart disease because of the victim experiencing psychological stress when being exposed to workplace incivility (Lim et al., 2008; Salin, 2003). In addition to the individual outcomes, the prevalence of workplace incivility may facilitate a hostile working environment. The experience or perception of this hostile environment may lead employees to reduce their efforts as well as spending a large amount of time venting to their colleagues about their experiences relating to perceived uncivil behaviour (Pearson \& Porath, 2005), and even retaliating with uncivil behaviour of their own. Workplace incivility may cause employees to withdraw; decrease their willingness to work; increase their absenteeism; as well as lead to a loss of productive time on the job, which will affect the desired outcomes of the organisation (Bartlett, Bartlett \& Reio, 2008). The relationships that have been established between workplace incivility and outcomes, such as work engagement, workplace bullying, job satisfaction, organisational commitment and turnover intention, were determined within the United States of America and other countries (Shim, 2015). No research on this specific topic has been conducted within the South African context. According to Keenan and Newton (1985), conflicts that are left unresolved at work are one of the factors that can cost organisations the most financially. This may be because of failure of management to address factors such as workplace incivility because of an inability to identify and manage such behaviour, which leads to a downward spiralling effect (Pearson \& Porath, 2005). In other words, workplace incivility left unchecked may lead to an escalation in behaviour of a deviant nature, that is, bullying.

Currently, no validated measures exist within the South African context to measure workplace incivility and to study its impact on employees and organisations. Therefore, the current study aimed to address this gap with the validation of a workplace incivility scale (WIS), based on the work of Leiter and colleagues in Canada (Leiter, Laschinger, Day \& Oore, 2011). This is important as the work ethics, values and beliefs of South African employees may differ from those within other countries (Foxcroft \& Roodt, 2009). Consequently, the WISs that have been used within North America should not be used irresponsibly within the South African context without proper evidence of validation. The main reason for this is that the results obtained could be unreliable and invalid; leading to a skewed picture of behaviour and incivility within South African organisations.

\section{Literature review Measuring workplace incivility}

The original WIS was developed in the United States of America by Cortina et al. (2001) in order to measure employees' experiences related to workplace incivility. Their sample comprised public sector employees, and results showed that the scale properties were acceptable with $71 \%$ of respondents indicating that they had experienced incivility in the past. However, as research progressed on workplace incivility and the need was identified to more clearly isolate the impact of specific sources of workplace incivility, the Cortina et al. (2001) scale was adapted by Laschinger and colleagues to measure employee perceptions of incivility from their supervisors (five items) and colleagues (five items) (Laschinger, Leiter, Day \& Gilin, 2009). In 2011, Leiter et al. (2011) also added five items to this scale measuring a third source of incivility: instigated incivility - measuring the employee's own instigated behaviour towards other employees (Blau \& Andersson, 2005). In other words, the final adapted scale that the current study sought to validate consisted of 15 items total (Leiter et al., 2011), clustered into three different categories measuring different sources of workplace incivility, that is, supervisor incivility, colleague incivility and instigated incivility, with five items each. Accordingly, the WIS was expected to reflect this 
three-factor structure based on the three sources of incivility measured by this scale:

Hypothesis 1: The workplace incivility scale consists of a three-factor structure.

\section{Discriminant validity: Workplace incivility and workplace bullying}

Table 1 presents a summary of the differences between workplace incivility and workplace bullying as derived from literature.

As mentioned earlier, workplace incivility and workplace bullying are both classified as workplace deviance but remain different conceptual phenomena. Workplace bullying is directed towards other employees and includes some of the following systematic patterns of behaviours: blatant insults, humiliation and social isolation (Cowie, Naylor, Rivers, Smith \& Pereira, 2002). Whereas, workplace incivility can be identified by the following three main criteria: Firstly, similar to bullying, workplace incivility is an act that is directed towards other employees rather than towards the organisation itself. Secondly, this behaviour is not acted out towards another individual with the specific purpose of harming him or her, that is, the intent is perceived as ambiguous, which is not the case with bullying which is purposeful. However, it is important to note that even though intention to harm is ambiguous, it does not mean that harm will be prevented (Estes \& Wang, 2008). Thirdly, the victim's perception of the intent of the action is one of the most important considerations as individuals respond to the perceived intent of the instigator (Hershcovis, 2010). Furthermore, with workplace bullying a clear power imbalance needs to be present and the frequency of the purposeful harmful behaviour needs to happen over an extended period of time (e.g. a minimum of 6 months; Van den Broeck, Baillien \& De Witte, 2011) - these are not prerequisites in the case of workplace incivility. Moreover, the victims of workplace bullying are often unable or unwilling to respond (Namie, 2003), whereas with workplace incivility instigated responses and escalations are possible (Blau \& Andersson, 2005; Leiter et al. 2011):

Hypothesis 2: Workplace incivility shows acceptable discriminant validity.

\section{Work engagement and workplace incivility}

Work engagement is described as the work-related state of mind characterised as being positive and rewarding
(Schaufeli, Bakker \& Salanova, 2006). It is evident that work engagement is important to all organisations as it leads to financial returns, a behaviour which is characterised by proactivity, as well as increased performance (Suleal, Fischmann \& Filipescu, 2012). It is characterised by three components: high levels of vigour (energy), dedication (devotion) towards one's work and also absorption (immersion) within one's work (Schaufeli et al., 2006), enabling employees to work optimally towards achieving organisational outcomes.

According to research conducted by Beattie and Griffin (2014), the Job Demands-Resources model - developed by Demerouti, Bakker, Nachreiner, and Schaufeli (2001) - states that workplace incivility is a psychosocial demand that employees experience in their work. As a result, it is considered to be an emotional demand and leads to the exhaustion of the emotional resources of the victim (Bakker \& Demerouti, 2007). Furthermore, the relationship between work engagement and workplace incivility has been explained by means of the self-enhancement theory (Chen et al., 2013). This theory states that humans seek contexts in which they are able to maintain a positive image of themselves and these individuals will also withdraw from contexts in which they are unable to maintain this positive self-image. This can be supported by the research study, which states that one-fourth $(25 \%)$ of individuals being exposed to workplace incivility will intentionally decrease the effort which they invest in their work, as well as $47 \%$ of employees decreasing the amount of time that they spend on their work (Pearson \& Porath, 2005). That being so, workplace incivility threatens the positive image the individuals have of themselves as well as their value and their worth. In other words, when workplace incivility occurs, and affects their positive image, this will lead to a decrease in their desire to participate in activities that are work-related, that is, their enthusiasm and dedication to their work decreases (Chen et al., 2013). Therefore, when employees experience workplace incivility, their work engagement levels are considered to be negatively affected (Dowden, 2015):

Hypothesis 3: Workplace incivility negatively predicts work engagement.

\section{Organisational commitment and workplace incivility}

Organisational commitment can be conceptualised as the degree to which the individual identifies with his or her organisation as well as the degree to which this employee is

TABLE 1: Summary of the differences between workplace incivility and workplace bullying.

\begin{tabular}{lll}
\hline Variable & Workplace incivility & Workplace bullying \\
\hline Intent of perpetrator & Perceived as ambiguous & Aggressive or damaging/harmful \\
Intensity & Low & High or severe \\
Frequency & Low & High \\
Power imbalance & Not a prerequisite & Prerequisite \\
Persistence & Not a prerequisite & Prerequisite \\
Response of victim & Instigated responses or escalation & Unable or unwilling \\
\hline
\end{tabular}

$\dagger$, Because of the established power imbalance. 
involved within this specific organisation (Steers, 1977). Furthermore, when employees have higher organisational commitment, they are more willing to exert effort in completing their work-related tasks, they identify more with the organisation and they are increasingly motivated to preserve their connection with their organisation (Mathis \& Jackson, 2000). Organisational commitment can be divided into three categories, namely affective, continuance and normative commitment (Meyer \& Allen, 1991). Affective commitment is when the employee has an emotional attachment to the organisation, whilst continuance commitment refers to the awareness that the individual has with regards to the costs associated with terminating their employment with the organisation. Lastly, normative commitment is when an employee feels obliged to continue their employment with the organisation (Meyer \& Allen, 1991). As a consequence, workplace incivility elicits emotional reactions from the victims. The current study therefore focused on the relationship between workplace incivility and affective organisational commitment.

Employees' levels of commitment to the organisation are influenced by variables such as the experience of uncivil behaviour. This is because of uncivil behaviour being considered to be unfair, which causes employees to decrease their commitment to the organisation (Barling \& Phillips, 1993). This is supported by the findings of Dowden (2015), which stated that $78 \%$ of employees have experienced a decrease in their organisational commitment levels after an instance in which they were victim to uncivil behaviour. Furthermore, when employees perceive their work environments to be promoters of workplace incivility, that is, aggressive in nature, they are likely to experience less commitment towards their organisation (Uzondu, Kelechi, Emmanuel \& Ebere, 2014). Duffy and Ferrier (2003) also found that there is a negative relationship between workplace incivility and organisational commitment. This is based on the grounds that when employees experience their environment as supportive, they experience more affective commitment towards the organisation (Rhoades, Eisenberger \& Armeli, 2001):

Hypothesis 4: Workplace incivility negatively predicts organisational commitment.

\section{Job satisfaction and workplace incivility}

Job satisfaction is the emotional response that an employee exhibits in terms of his or her job and situation (Ayeni \& Popoola, 2007). These emotional responses can be influenced by employees' perception of whether their job is fulfilling their expectations. In other words, job satisfaction cannot be seen, it can only be inferred. Research has shown that workplace incivility experienced from both the perspectives of the victim and instigator has a negative relationship with the satisfaction these individuals experience related to their jobs (Cingöz \& Kaplan, 2015). However, when these individuals experience their work environment as negative and hostile, they will develop a negative attitude or emotional state towards their job. These employees will therefore engage in behaviour that reflects their frustration, their difficulty in learning as well as decreased job satisfaction (Cingöz \& Kaplan, 2015). This is supported by the research of Cortina et al (2001) in which it is indicated that when workplace incivility increases, so does employees' negative emotional response to their jobs, that is, their job satisfaction decreases:

Hypothesis 5: Workplace incivility negatively predicts job satisfaction.

\section{Turnover intention and workplace incivility}

Intention to leave occurs when employees of the organisation consider terminating their employment with the specific organisation based on their own free will (Shim \& Chang, 2012). Turnover intention can be divided into two categories, namely voluntary and involuntary turnover, which can be influenced by the party (employer or employee) who makes the decision with regard to the continuation or termination of employment (Price, 1977). The current study will focus on the relationship between turnover intention, which is voluntary, and workplace incivility. Workplace incivility is said to increase distrust and decrease positive exchanges between co-workers; in other words, when employees perceive such negative relationships within the working environment, they are more likely to leave the organisation (Shim, 2015). According to Glendinning (2001), 50\% of employees who have experienced incivility have considered leaving the organisation and $12 \%$ actually terminate their employment with the organisation:

Hypothesis 6: Workplace incivility positively predicts turnover intention.

\section{Research design Research approach}

For the purpose of this study, a quantitative research approach was used, indicating that the variables of the study were measured in order to analyse and compare results. This study specifically followed a cross-sectional survey design (Du Plooy, 2002). A cross-sectional design was suitable as variables were measured simultaneously, and this allowed for assessing inter-relationships between variables (Struwig \& Stead, 2001). Data were therefore collected at a fixed point in time.

\section{Research method Research participants}

Employees within the banking industry were the target population for the study. The large organisation, which participated was selected based on their availability and willingness to participate. Additionally, the employees who participated in the study were also selected based on their willingness and availability. Thus, convenience sampling was used in the study (Teddie \& Yu, 2007). Because the study 
used a quantitative research method, the study aimed to include at least 300 participants ( 345 achieved). The participants who were included in the study were diverse in terms of characteristics such as gender, age, race, language and marital status.

Table 2 presents a breakdown of the participants comprising the sample.

The mean age of participants was 35.17 [standard deviation $(\mathrm{SD})=9.79]$. The sample consisted of $60.90 \%$ female participants and $34.80 \%$ male participants. In terms of ethnicity, $43.80 \%$ of participants were black employees, $27 \%$ were white employees, $11 \%$ were mixed-race employees, whilst only $0.90 \%$ participants were Asian employees. From these participants, approximately $9.00 \%$ spoke Setswana and $34.50 \%$ of the participants indicated English as their

TABLE 2: Characteristics of the participants $(N=345)$.

\begin{tabular}{|c|c|c|c|}
\hline Item & Category & $f$ & $\%$ \\
\hline \multirow[t]{3}{*}{ Gender } & Female & 210 & 60.90 \\
\hline & Male & 120 & 34.80 \\
\hline & Missing values & 15 & 4.30 \\
\hline \multirow[t]{7}{*}{ Ethnicity } & Black & 151 & 43.80 \\
\hline & White & 93 & 27.00 \\
\hline & Mixed-race & 36 & 11.00 \\
\hline & Indian & 42 & 12.80 \\
\hline & Asian & 3 & 0.90 \\
\hline & Other & 2 & 0.60 \\
\hline & Missing values & 18 & 5.20 \\
\hline \multirow[t]{6}{*}{ Household } & Single & 87 & 25.20 \\
\hline & Married or living with a partner & 182 & 52.80 \\
\hline & Divorced or separated & 21 & 6.10 \\
\hline & Living with parents & 40 & 11.60 \\
\hline & Widowed & 1 & 0.30 \\
\hline & Missing values & 14 & 4.10 \\
\hline \multirow[t]{5}{*}{ Education } & Grade 12 & 104 & 30.10 \\
\hline & Degree (Graduate or Honours) & 107 & 31.00 \\
\hline & Postgraduate degree & 29 & 8.40 \\
\hline & Diploma & 86 & 24.90 \\
\hline & Missing values & 19 & 5.50 \\
\hline \multirow[t]{13}{*}{ Language } & Afrikaans & 71 & 20.60 \\
\hline & English & 119 & 34.50 \\
\hline & Sepedi & 25 & 7.20 \\
\hline & Sesotho & 19 & 5.50 \\
\hline & Setswana & 31 & 9.00 \\
\hline & siSwati & 3 & 0.90 \\
\hline & Tshivenda & 11 & 3.20 \\
\hline & isiNdebele & 0 & 0.00 \\
\hline & isiXhosa & 15 & 4.30 \\
\hline & isizulu & 28 & 8.10 \\
\hline & isiTsonga & 6 & 1.70 \\
\hline & Other & 3 & 0.90 \\
\hline & Missing values & 14 & 4.10 \\
\hline \multirow[t]{8}{*}{ Employment } & Less than 1 year & 33 & 9.60 \\
\hline & $1-5$ years & 163 & 47.20 \\
\hline & $5-10$ years & 72 & 20.90 \\
\hline & 10-15 years & 27 & 7.80 \\
\hline & $15-20$ years & 17 & 4.90 \\
\hline & $20-25$ years & 9 & 2.60 \\
\hline & More than 25 years & 10 & 2.90 \\
\hline & Missing values & 14 & 4.10 \\
\hline
\end{tabular}

$f$, frequency. home language. Furthermore, 52.80\% of the participants were married or living with their partner and one of the participants was widowed. The majority of the sample had obtained a degree, either a graduate degree or honours degree $(31.00 \%)$, followed by $30.10 \%$ who have obtained a Grade 12 qualification (general high school education). In terms of the participants' employment with the organisation in the banking industry, $47.20 \%$ of the participants were employed between one and five years, whilst $2.60 \%-$ $2.90 \%$ of participants were employed for 25 years or more, respectively.

\section{Measuring instruments}

A biographical questionnaire was used in order to gather all the necessary information pertaining to the participants, such as age, gender, ethnicity, home language, educational level, marital status as well as applicable employment information.

Workplace incivility was measured with an adapted scale created by Leiter et al. (2011). The scale measures uncivil behaviour such as disrespect and rudeness in terms of employee perceptions and experiences thereof. The scale consists of three subscales, which isolate three sources of workplace incivility: (1) supervisor incivility, (2) colleague incivility and (3) instigated incivility. All the scales used the same set of questions, for example, in terms of instigated incivility: 'How frequently have you: Ignored or excluded another person from professional camaraderie?' and for supervisor incivility: 'Please indicate how frequently you have encountered the following behaviours from your supervisor'. Participants were required to respond to these items using a 5-point scale where 0 represented 'Never' and 4 represented 'Most of the time'. This scale has shown acceptable reliability coefficients for supervisor incivility ( $\alpha=0.84 ; 0.85)$, colleague incivility $(\alpha=0.85 ; 0.86)$ and instigated incivility $(\alpha=0.74 ; 0.80)$ (Leiter et al., 2011).

Workplace bullying was measured with a short-form bullying scale measured with items from the South African Employee Health and Wellness Survey, which was originally developed by Rothmann and Rothmann (2006). The scale consists of six items that measure experiences related to direct interpersonal bullying experiences from co-workers (e.g. 'How often do you feel intimidated by your co-workers?'; 'How often have you felt your co-workers are threatening you?'). Participants are required to rate their experiences on a scale of one representing 'Never' and four representing 'Always'. Rothmann and Rothmann (2006) reported Cronbach's alpha reliabilities for this scale ranging from 0.81 to 0.86 .

Work engagement was measured with the 9-item short-form Utrecht Work Engagement Scale (UWES) developed by Schaufeli and Bakker (2003). The UWES consists of nine items, which can be divided into three vigour items (e.g. 'When I get up in the morning, I feel like going to work'), three dedication items (e.g. 'I am proud of the work that I do') and three absorption items (e.g. 'I am immersed in my work'), as these are considered the three components of 
work engagement (Schaufeli \& Bakker, 2003). Respondents are required to respond based on a 7-point frequency-rating scale ranging from zero which is 'Never' and six which is 'Always'. Based on the research conducted by Storm and Rothmann (2003), the UWES has been successfully implemented within the South African context with acceptable reliability coefficients.

Organisational commitment was measured by means of the scale proposed by Allen and Meyer (1990). This is a 5-point scale ranging from one representing 'Strongly disagree' to five representing 'Strongly agree'. Affective commitment is measured by eight items and is concerned with the emotional affect that the individual has towards the organisation (e.g. 'This organisation has a great deal of personal meaning for me'). In the current study, the main focus was placed on affective commitment based on the grounds that incivility may affect the individuals' emotional state. This scale has provided acceptable Cronbach's alphas within the South African context (Bagraim, 2003).

Job satisfaction was measured with a 3-item scale. This scale was developed by Hellgren, Sjöberg and Sverke (1997) and should be responded to on the basis of a 5-point scale, which ranges from one representing 'Strongly disagree' to five representing 'Strongly agree'. This scale measures the individual's satisfaction with his or her job (e.g. 'I enjoy being at my job'). Within the South African context, the scale has provided a Cronbach's alpha of 0.80 (Pienaar, Sieberhagen \& Mostert, 2007).

Turnover intention was measured with the scale developed by Sjöberg and Sverke (2000). It consists of three items (e.g. 'I feel that I could leave this job'), and the participants were required to respond based on a 5-point scale, which ranges from one (Strongly disagree) to five (Strongly agree). In South Africa, this scale provided a Cronbach's alpha coefficient of 0.81 (Chidyamakono, 2010).

\section{Research and ethical procedure}

Ethical clearance was obtained for the study from the University's Faculty Research Committee (EMS15/06/ 18-01/02). The relevant parties, that is, human resources department, data privacy department and line managers from a large South African bank were approached to explain the purpose of the research and gain permission to conduct the research at their place of work. Three large departments were identified for collecting data. A total of 400 booklets were printed and distributed by hand by the researcher to each employee in the three departments. The process of informed consent was followed by providing the employee with information on the purpose of the study in order to make an informed choice regarding their willingness to partake in the survey. The survey did not necessitate the participants to identify themselves personally, and as such, all surveys remained anonymity and confidentiality. Participants were also informed of their right to cease participation in the survey at any moment without any negative repercussions, as participation was voluntary. A secure box was provided to drop off the survey booklets in each department. Each participant also received an envelope in order to secure their booklet before depositing the envelope in the box. A total of 345 completed booklets were collected from the organisation indicating a response rate of $86 \%$. The data were then captured and screened for any errors before statistical analysis commenced.

\section{Statistical analysis}

Descriptive statistics and structural equation modelling methods were implemented with Mplus 7.31 (Muthén \& Muthén, 2015). For the descriptive statistics, the items' means, SDs, skewness, kurtosis and minimum- and maximum-scale values were generated with the TYPE=BASIC function. Skewness and kurtosis values would be considered problematic for any item values above 2 or below -2 (George \& Mallery, 2010) see Table 2 .

Confirmatory factor analysis (CFA) was implemented within a structural equation modelling framework to construct the latent variable measurement models (Brown, 2015), that is, the competing factor structures and the proceeding structural regressions for the structural model based on the most appropriate factor structure. CFA was the most fitting technique to construct the latent variables for the study as the factor structures of the scales used were available from previous peer-reviewed literature - with the added advantage that latent variables account for measurement error which other techniques (e.g. ordinary least squares and multiple regression) do not (Brown, 2015).

The robust version of the maximum likelihood estimator (MLR) was used as an estimation method as it is robust against the possibility of data non-normality (Muthén \& Muthén, 2015). The following indices were considered for the fit of the CFA models to the data: The comparative fit index (CFI; acceptable values 0.90 and above), the TuckerLewis index (TLI; acceptable values 0.90 and above), the root mean square error of approximation (RMSEA; acceptable values below 0.08) and the standardised root mean residual (SRMR; acceptable values of 0.05 and below) (Van de Schoot, Lugtig, \& Hox, 2012). As the MLR estimation method was implemented, direct comparison by chi-squared values for models cannot be accurately interpreted - therefore, preference was given to the Akaike information criterion (AIC) and Bayesian information criterion (BIC) for model comparison (Bollen, Harden, Ray \& Zavisca, 2014).

A correlation matrix was also generated for the latent variables, and effect sizes for the correlations would be considered as a medium effects for values of $0.30-0.49$ and large effects for values between 0.50 and 0.84 (Cohen, 1992). For discriminant validity $\left(H_{2}\right)$, any correlation of 0.85 and above would be considered problematic and an investigation 
into discriminant validity would have to be performed (Brown, 2015). Finally, regressions were added to the final (best fitting) measurement model in line with the research hypotheses on the relationships between workplace incivility and the outcomes variables to constitute the structural model. The significance and direction of the standardised beta coefficients of the regressions would then be considered for the investigation of predictive validity.

Figure 1 presents the structural model that was tested to investigate the predictive hypotheses.

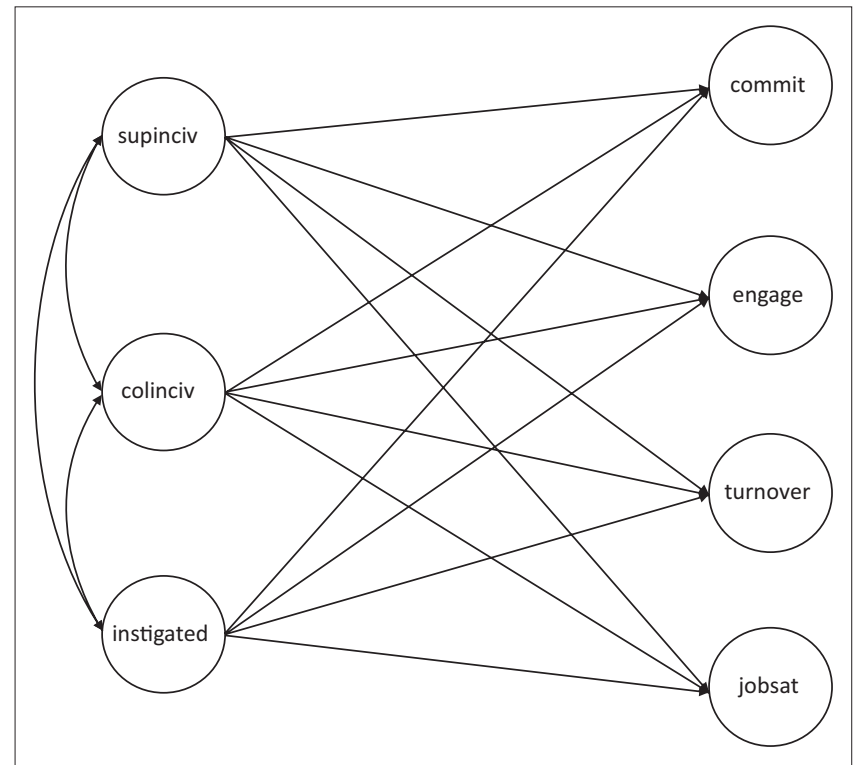

FIGURE 1: Structural model for the predictive validity investigation.

\section{Results \\ Descriptive statistics for the items}

Table 3 provides the means, SDs, skewness, kurtosis and minimum and maximum values on the responses for each of the item scales of the adapted WIS.

The item descriptive statistics revealed that most of the individuals tend to score towards the lower end of the scales, that is, less incivility. The majority of the items had acceptable levels of skewness and kurtosis compared to the set cut-off. However, in terms of kurtosis, items perincivil2 (2.83) and perincivil5 (3.23) were above the set cut-off criteria. This indicated that the robust MLR was an applicable and informed choice for continuing with the SEM implementations as there was evidence of non-normality in the data.

\section{Confirmatory factor analysis Factor structure comparison and item loadings of the scale}

Table 4 presents the fit of the measurement models to the data, that is, the competing measurement models.

As can be seen from Table 4, the three-factor structure was a substantially better model, when compared to the competing one-factor structure, as shown by the AIC (13049.99) and BIC (13201.34) values, which were substantially lower for the threefactor model. AIC and BIC values were preferred because of the estimator used (MLR) - as a regular chi-square comparison cannot be done when implementing this estimation method,

TABLE 3: Descriptive statistics for the items of the workplace incivility scale.

\begin{tabular}{|c|c|c|c|c|c|c|}
\hline Item & $\mathbf{M}$ & SD & Skewness & Kurtosis & Minimum value $(\%)$ & Maximum value (\%) \\
\hline \multicolumn{7}{|c|}{ Supervisor incivility } \\
\hline supincivil1 & 1.58 & 1.31 & 0.38 & -0.98 & 26.53 & 10.50 \\
\hline supincivil2 & 1.07 & 1.31 & 0.97 & -0.29 & 49.56 & 8.16 \\
\hline supincivil3 & 1.09 & 1.33 & 0.89 & -0.52 & 50.58 & 7.89 \\
\hline supincivil4 & 1.23 & 1.29 & 0.75 & -0.59 & 39.94 & 8.16 \\
\hline supincivil5 & 0.83 & 1.21 & 1.27 & 0.39 & 60.06 & 4.96 \\
\hline \multicolumn{7}{|c|}{ Colleague incivility } \\
\hline colincivil1 & 1.19 & 1.12 & 0.68 & -0.37 & 34.30 & 3.78 \\
\hline colincivil2 & 0.92 & 1.09 & 0.98 & 0.05 & 49.13 & 2.62 \\
\hline colincivil3 & 0.89 & 1.06 & 1.01 & 0.06 & 48.84 & 1.74 \\
\hline colincivil4 & 0.99 & 1.11 & 1.01 & 0.22 & 43.60 & 3.78 \\
\hline colincivil5 & 0.83 & 1.07 & 1.21 & 0.62 & 52.05 & 2.63 \\
\hline \multicolumn{7}{|c|}{ Instigated incivility } \\
\hline perincivil1 & 1.05 & 1.04 & 0.73 & -0.14 & 38.08 & 2.33 \\
\hline perincivil2 & 0.56 & 0.93 & 1.82 & 2.83 & 65.70 & 1.74 \\
\hline perincivil3 & 0.61 & 0.91 & 1.55 & 1.97 & 61.05 & 1.45 \\
\hline perincivil4 & 0.97 & 1.03 & 0.82 & -0.19 & 42.73 & 1.45 \\
\hline perincivil5 & 0.51 & 0.91 & 1.92 & 3.23 & 69.97 & 1.75 \\
\hline
\end{tabular}

M, mean; SD, standard deviation.

TABLE 4: Results of the measurement models for the adapted WIS scale of Leiter and colleagues.

\begin{tabular}{|c|c|c|c|c|c|c|c|}
\hline Model & $d f$ & CFI & TLI & RMSEA & SRMR & AIC & BIC \\
\hline 1. One factor & 45 & 0.60 & 0.54 & 0.15 & 0.12 & 13908.81 & 14081.64 \\
\hline 2. Three factors & 48 & 0.93 & 0.92 & 0.06 & 0.04 & 13049.99 & 13201.34 \\
\hline
\end{tabular}

$d f$, degrees of freedom; CFI, comparative fit index; TLI, Tucker-Lewis index; RMSEA, root mean square error of approximation; SRMR, standardised root mean residual; AIC, Akaike Information Criterion; BIC, Bayesian Information Criterion. 
but it can also clearly be seen from all indices that the threefactor model best fitted the data - as expected. The correlations between the three factors were also acceptable and sufficiently large without concerns of discriminant validity (see Table 6 for correlations). This evidence supported $H_{1}$.

Table 5 presents the factor loadings for the items of the threefactor model.

All the items loaded significantly on their respective factors ( $\lambda$ values $>0.60)$, and the latent factors explained a large amount of variance in all the corresponding items $\left(R^{2} \mathrm{~s} \geq 0.37\right.$; at least $37 \%$ ). This provided further supportive evidence for $H_{1}$. Specifically, for supervisor incivility, the highest factor loading was shown to be item three [supincivil3: $\lambda=0.88$, standard error $\left.(\mathrm{SE})=0.02, R^{2}=0.78\right]$. Similarly, item three for colleague incivility and instigated incivility also had the highest loadings and explained variances (colincivil3: $\lambda=0.84, \mathrm{SE}=0.03, R^{2}=0.70$; perincivil3; $\lambda=0.85 ; \mathrm{SE}=0.03$; $\left.R^{2}=0.72\right)$. This item, in all three sources of incivility, was concerned with addressing individuals in an unprofessional manner either privately or publically.

\section{Reliability coefficients and correlation matrix for the study variables}

Given the results of the factor structure of the WIS, the study continued to investigate the remaining hypotheses with the three-factor structure of workplace incivility. The remaining

TABLE 5: Standardised loadings for the latent factors.

\begin{tabular}{llcccc}
\hline Factor & Item & Loading & SE & $\boldsymbol{p}$ & $\boldsymbol{R}^{\mathbf{2}}$ \\
\hline Supervisor & supincivil1 & 0.72 & 0.04 & 0.001 & 0.51 \\
& supincivil2 & 0.82 & 0.03 & 0.001 & 0.67 \\
& supincivil3 & 0.88 & 0.02 & 0.001 & 0.78 \\
& supincivil4 & 0.85 & 0.02 & 0.001 & 0.72 \\
& supincivil5 & 0.76 & 0.03 & 0.001 & 0.58 \\
Colleague & colincivil1 & 0.77 & 0.03 & 0.001 & 0.59 \\
incivility & colincivil2 & 0.80 & 0.04 & 0.001 & 0.64 \\
& colincivil3 & 0.84 & 0.03 & 0.001 & 0.70 \\
& colincivil4 & 0.82 & 0.03 & 0.001 & 0.67 \\
& colincivil5 & 0.73 & 0.04 & 0.001 & 0.54 \\
Instigated & perincivil1 & 0.67 & 0.04 & 0.001 & 0.45 \\
incivility & perincivil2 & 0.78 & 0.04 & 0.001 & 0.61 \\
& perincivil3 & 0.85 & 0.03 & 0.001 & 0.72 \\
& perincivil4 & 0.68 & 0.05 & 0.001 & 0.46 \\
& perincivil5 & 0.61 & 0.12 & 0.001 & 0.37 \\
\hline
\end{tabular}

Notes: $\mathrm{SE}$, standard error. All $p$-values $<0.001$ study variables were added to the three-factor measurement model and the following was found: The total measurement model also fitted the data adequately $(\mathrm{CFI}=0.91$; $\mathrm{TLI}=0.90$; RMSEA $=0.05 ;$ SRMR $=0.05$ ). Furthermore, Cronbach's alpha reliability coefficient was calculated as indicators of internal consistency for the variables and is presented on the diagonal of the correlation matrix in brackets.

Table 6 presents the correlation matrix for the study variables.

As can be seen on the diagonal of the matrix, all the reliability coefficients were acceptable $(\alpha \geq 0.70$; Nunnally \& Bernstein, 1994). Specifically, this was the case for the three factors of workplace incivility. In terms of the correlations, all three WIS factors correlated with each other with large effect: Supervisor incivility had a positive relationship with both colleague incivility $(r=0.54)$ and instigated incivility $(r=0.50)$; and colleague incivility was also positively correlated with instigated incivility $(r=0.67)$. Furthermore, all three WIS factors were correlated with bullying, that is, bullying was correlated with supervisor incivility ( $r=0.44$; medium effect), colleague incivility $(r=0.67$; large effect) and instigated incivility $(r=0.48$; medium effect). These correlations provided evidence of convergent validity for the workplace incivility factors.

Additionally, the workplace incivility factors were negatively correlated with positive outcomes and positively correlated with negative outcomes, as was and would be expected. For example, supervisor incivility was negatively correlated with job satisfaction $(r=-0.37)$, positively correlated with turnover intention $(r=0.45)$ and negatively correlated with organisational commitment $(r=-0.35)$.

To determine discriminant validity, the correlations between the variables were also considered and all the correlations were below the 0.85 guideline provided by Brown (2015). Indeed, all correlations were within acceptable parameters, and further investigation was not necessitated. This supported $H_{2}$.

\section{Structural model fit and regression results}

For predictive validity, regression paths were added to the measurement model in line with the study hypotheses, and the following was found: The model showed an acceptable fit to the data $(\mathrm{CFI}=0.91 ; \mathrm{TLI}=0.90 ; \mathrm{RMSEA}=0.06$; $\mathrm{SRMR}=0.05)$. The results of the regressions are given in Table 7 .

TABLE 6: Reliabilities and correlation matrix for the latent variables.

\begin{tabular}{|c|c|c|c|c|c|c|c|c|}
\hline Variables & 1 & 2 & 3 & 4 & 5 & 6 & 7 & 8 \\
\hline 1. Supervisor incivility & $(0.91)$ & - & - & - & - & - & - & - \\
\hline 2. Colleague incivility & $0.54^{\mathrm{b}}$ & $(0.89)$ & - & - & - & - & - & - \\
\hline 3. Instigated incivility & $0.50^{\mathrm{b}}$ & $0.67^{\mathrm{b}}$ & $(0.83)$ & - & - & - & - & - \\
\hline 4. Bullying & $0.44^{\mathrm{a}}$ & $0.67^{b}$ & $0.48^{\mathrm{a}}$ & $(0.84)$ & - & - & - & - \\
\hline 5. Commitment & $-0.35^{a}$ & -0.28 & -0.29 & -0.21 & $(0.76)$ & - & - & - \\
\hline 6. Work engagement & $-0.34^{a}$ & -0.25 & $-0.32^{\mathrm{a}}$ & -0.26 & $0.59^{b}$ & $(0.85)$ & - & - \\
\hline 7. Turnover intention & $0.45^{\mathrm{a}}$ & 0.23 & 0.25 & 0.21 & $-0.62^{b}$ & $-0.57^{b}$ & $(0.79)$ & - \\
\hline 8. Job satisfaction & $-0.37^{a}$ & -0.28 & $-0.36^{a}$ & -0.26 & $0.64^{\mathrm{b}}$ & $0.74^{\mathrm{b}}$ & $-0.69^{b}$ & (0.88) \\
\hline
\end{tabular}

Notes: Cronbach's reliability coefficients in brackets on the diagonal. All correlations statistically significant at $p<0.001$.

a, Medium practical effect.

b, Large practical effect. 
TABLE 7: Regression results for the structural model.

\begin{tabular}{llll}
\hline Structural path & $\beta$ & SE & Result \\
\hline Supervisor incivility $\rightarrow$ Work engagement & -0.25 & 0.08 & 0.003 \\
Supervisor incivility $\rightarrow$ Organisational commitment & -0.26 & 0.08 & 0.001 \\
Supervisor incivility $\rightarrow$ Job satisfaction & -0.26 & 0.08 & 0.001 \\
Supervisor incivility $\rightarrow$ Turnover intention & 0.45 & 0.07 & 0.001 \\
Colleague incivility $\rightarrow$ Work engagement & 0.02 & 0.10 & 0.841 \\
Colleague incivility $\rightarrow$ Organisational commitment & -0.06 & 0.10 & 0.574 \\
Colleague incivility $\rightarrow$ Job satisfaction & 0.03 & 0.10 & 0.792 \\
Colleague incivility $\rightarrow$ Turnover intention & -0.07 & 0.09 & 0.461 \\
Instigated incivility $\rightarrow$ Work engagement & -0.20 & 0.11 & Not significant \\
Instigated incivility $\rightarrow$ Organisational commitment & -0.12 & 0.10 & Not significant \\
Instigated incivility $\rightarrow$ Job satisfaction & -0.25 & 0.10 & Not significant \\
Instigated incivility $\rightarrow$ Turnover intention & 0.07 & Not significant & 0.232 \\
\hline
\end{tabular}

$\beta$, beta coefficient; SE, standard error; $p$, two-tailed statistical significance.

$H_{5}$ was only partially supported, as only supervisor incivility predicted work engagement negatively $(\beta=-0.25$, $\mathrm{SE}=0.08, p=0.003)$. However, instigated incivility was a borderline statistically significant case in predicting work engagement negatively $(\beta=-0.21, \mathrm{SE}=0.11, p=0.049)$. Specifically, supervisor incivility also predicted organisational commitment $\left(\beta=-0.26, \mathrm{SE}=0.08, p=0.001\right.$; supporting $\left.H_{6}\right)$ and job satisfaction $(\beta=-0.26, \mathrm{SE}=0.08, p=0.001$; supporting $\left.H_{7}\right)$ negatively - but predicted turnover intention positively $\left(\beta=0.45, \mathrm{SE}=0.07, p=0.001\right.$; supporting $\left.H_{8}\right)$. Colleague incivility did not significantly predict any of the outcome variables ( $p$ values $>0.05$ ). The only remaining significant relationship was that of instigated incivility predicting job satisfaction negatively $(\beta=-0.25, \mathrm{SE}=0.10, p=0.014)$. Therefore, taken together, all the predictive hypotheses $\left(H_{3}-H_{6}\right)$ were only partially supported.

\section{Discussion}

\section{Outline of the results}

The study aimed to validate a WIS (Leiter et al., 2011). This was achieved by investigating the reliability of the measure along with the validity thereof - including investigations into the factor structure, convergent validity, discriminant validity as well as predictive validity with the outcome variables of work engagement, organisational commitment, job satisfaction and turnover intention.

Preliminary analysis in the form of item descriptive statistics revealed that the majority of participants scored on the lower end of the item scales (Almost never or Seldom; 70.66\%), that is, uncivil behaviours were not frequent - as expected from literature. However, a minority did report experiencing incivility more frequently (often or most of the time; on average $12.76 \%$ ). This attests to a work environment where the majority of employees, in general, get along well. Nevertheless, it also indicates the power incivility can have when it is perceived by employees, as these employees may be higher risk recipients who feel excluded from being a valid member of the organisational community, which also thwarts their need for belonging (Leiter, 2012). Over time, this may even evolve into full-blown bullying (Van den Broeck et al., 2011).

The first hypothesis of the study set out to confirm that the WIS consists of a three-factor structure based on the three sources of incivility (Leiter et al., 2011), compared to a potential one-factor structure of incivility. By using CFA, evidence showed that the proposed three-factor structure was a substantially better fit to the data than the competing one-factor structure. This is in line with the findings of Leiter et al. (2011), who operationalised the WIS used in this study as a three-factor structure (based on sources of incivility). All the scales were also found to be reliable. Furthermore, the three factors were correlated with one another with large effect size. Specifically, the results indicated that there was a positive relationship between supervisor incivility and the other two factors, namely colleague incivility and instigated incivility. The results also found a positive relationship between colleague incivility and instigated incivility.

The second hypothesis was concerned with establishing evidence for discriminant validity between workplace incivility and workplace bullying, as the two constructs are often mistaken for one another (Branch, 2008). Workplace bullying differs from workplace incivility because of its purposeful intent, severe intensity, increased frequency and persistence (Hershcovis, 2010; also see Table 1). Discriminant validity between workplace bullying and workplace incivility was established by taking into consideration the correlations between the variables. The correlations were all practically significant, but well below the guideline of 0.85 , which was provided by Brown (2015). This is in line with research that has found a similar correlation between workplace incivility and bullying (Giorgi, 2008). The hypothesis was therefore supported as the correlations fell within the acceptable parameters, and further investigation into discriminant validity between these variables was not necessitated, as results indicated two connected, yet separate, constructs. In terms of explaining the relationship workplace incivility and workplace bullying, the research of Bibi, Karim and Din, (2013) found that employees exposed to uncivil behaviours feel provoked and that many of these employees will act in a way to get even with the instigator (Dowden, 2015), indicating the downward spiralling effect argued by Andersson and Pearson (1999).

Furthermore, the correlation results indicated that as the scores on workplace incivility factors increased, they had negative relationships with positive outcome variables, 
whilst having positive relationships with negative outcome variables. For example, supervisor incivility had a negative relationship with job satisfaction as outcome variable. This is supported by previous research study by Dowden (2015), which found that employees who perceive workplace incivility have reported a decrease in their job satisfaction levels, specifically supervisor and colleague incivility (Laschinger et al., 2009). In other words, if supervisor incivility increases, the employee's satisfaction with his or her job will decrease as it stimulates employees' negative feelings (Taylor, 2010). Lastly, in line with previous research (Laschinger et al., 2009), supervisor incivility also had a negative relationship with organisational commitment indicating that the employee's commitment to the organisation will decrease if he or she experiences incivility from his/her supervisor; this may be as a result of the employee experiencing the working environment to be hostile and the organisation being indifferent towards what is experienced by them (Bartlett et al., 2008; Taylor, 2010). Supervisor incivility also had a positive relationship with turnover intention, which indicated that if supervisor incivility increases, the employees' intention to leave the organisation will also increase. Research has shown that $12 \%$ of employees actually leave the organisation after being exposed to workplace incivility (Glendinning, 2001).This could be because of the employee wanting to escape the environment as a result of the perceived incivility from the supervisor towards them.

With regard to work engagement (Hypothesis 3), the regression results indicated that only supervisor incivility was a significant negative predictor of work engagement. This may be explained in the context of the Job DemandsResources model, as supervisory support is a social job resource (Bakker \& Demerouti, 2007; Demerouti et al., 2001). Therefore, when employees perceive incivility from their supervisors, their experience of the social aspect of supervisor support is affected and they are likely to experience an imbalance in these resource-affecting work engagement levels (Beattie \& Griffin, 2014). However, Hypothesis 3 was only partially supported as the other two sources of workplace incivility did not significantly predict work engagement, although instigated incivility was a borderline statistically significant case in negatively predicting work engagement $(p=0.058)$. This indicates the possibility that employees who are instigated towards being uncivil towards co-workers are more likely to be less engaged - as also indicated by the correlation found between the two variables, that is, a negative correlation of medium effect size. This may be because of psychological energy being diverted from work to pondering instigated behaviours.

With regard to organisational commitment (Hypothesis 4), the hypothesis was also only supported partially as supervisor incivility was once again the only significant negative predictor of organisational commitment. This may be because of the fact that when supervisors treat other employees in an uncivil manner they tend to experience the working environment as unsupportive and therefore a decrease in their affective commitment towards the organisation is the result (Rhoades et al., 2001). This is supported by Barling and Phillips (1993) who stated that workplace incivility is perceived to be unfair treatment and as a consequence impacts employee organisational commitment.

In relation to job satisfaction, Hypotheses 5 was also partially supported as supervisor incivility and instigated incivility both were significant in negatively predicting job satisfaction. The reason may be that the employee acts in an uncivil way so as to give expression to his or her dissatisfaction with his or her job situation, as well as experiencing a lack of civility from authority figures, which contributes to a negative attitude that the employee experiences towards his or her job (Holm, 2014). Lastly, supervisor incivility was again the only significant predictor in terms of turnover intention (Hypothesis 6), that is, positively predicted turnover intention. Similar results were found by Laschinger et al (2009) as supervisor incivility was the strongest predictor of turnover intention. Employees may feel that their supervisor is treating them in an unfair manner, thus feeling that they no longer want to continue their employment with the organisation as the supervisor is making it difficult for them to stay (Shim, 2015).

Colleague incivility did not significantly predict any of the outcome variables ( $p^{\prime}$ s $\left.>0.05\right)$. In the absence of causal evidence, the following potential reasons must remain speculative. Even though the correlations revealed practically significant effects with supervisor incivility and instigated incivility (i.e. where incivility is present, all three types appear evident), colleague incivility may not have been a significant predictor of any of the outcome variables based on the grounds that with workplace incivility even though no clear power imbalance between the victim and the perpetrator needs to exist it may play an important role on the effect on outcomes (Pearson \& Porath, 2005). Supervisors are valued members within the organisation, and often, employees look up to these supervisors as role models with significant decision-making power, which may be a big contributor towards supervisor incivility being a significant predictor of all the outcome variables, as the victim may perceive that the supervisor dislikes them or similar. Therefore, as there is little power imbalance between colleagues in terms of incivility, the victims of such behaviour may not be affected to such a negative extent compared to when they perceive that their supervisors treat them in an uncivil manner (Pearson \& Porath, 2005).

\section{Practical implications}

The current study provided evidence of the validity and the reliability of a WIS pertaining to measurement in the South African banking industry. If organisations are aware of workplace incivility, they can consider strategies that can be implemented in order to eliminate the impact it can have on the organisational outcomes, which were highlighted in the study, that is, workplace bullying, work engagement, organisational commitment, job satisfaction as well as 
turnover intention. Specifically, the 'broken windows' perspective of neighbourhood policing might be an applicable analogy to consider and apply in this situation. This perspective holds that if broken windows (minor crimes; occurrences of incivility) in a neighbourhood (organisation) are addressed (e.g. by means of awareness and policies), the overall disorder that generates and sustains more serious crimes (more intense forms of workplace deviance, e.g. bullying) will decrease (cf. Welsh, Braga \& Bruinsma, 2015).

The study also showed that workplace incivility perceived by employees from supervisors proved to be most problematic on outcomes. Therefore, if organisations are to address workplace incivility, it is necessary to address it in a sensitive manner as to not aggravate supervisors, which may cause them frustration (as it is based on the perception of the victim), which in turn could lead them to engage in more intense forms of workplace deviance such as workplace bullying (Andersson \& Pearson, 1999). It is also important to note that workplace incivility may be facilitated by various other factors such as the environment in which these employees function (Bibi et al., 2013), which may also require consideration by management.

\section{Limitations and recommendations of the study}

The current study is not without limitations. The first main limitation involves the use of a cross-sectional survey design. This design restricts the study from definitively establishing relationships of a predictive (causal) nature. Thus, in order to be able to explore such relationships, it is necessary that future research is longitudinal in nature. This will enable researchers to definitively investigate the direction and causality of the relationships (Taris \& Kompier, 2006). Another causal relationship that could be investigated is if workplace incivility predicts workplace bullying over a time lag of half a year, for example.

The second main limitation is concerned with the participants of the current study. The sample consisted of participants within a single large organisation within the banking industry. Furthermore, the sampling strategy was convenience sampling, which is a non-probability strategy which is not as accurate a representation of the population as random sampling would be (random probability sampling). Therefore, caution is advised in making generalisations pertaining to this phenomenon in other industries. Future research in other industries is therefore suggested with stratified sampling as a potential sampling strategy.

The final main limitation is the implementation of a selfreport questionnaire in collecting data, which has received much criticism regarding measurement bias matters (Spector, 1994). This is a limitation because social desirability is likely to occur when items of a socially sensitive nature are used within a questionnaire, for example, when having to complete a self-report questionnaire on workplace deviance (Van de Mortel, 2008). This method was used because of the fact that self-report questionnaires are considered to be a method which is common in terms of the exploration of latent constructs such as workplace incivility - which is also a subjective perception of individuals (Podsakoff, MacKenzie, Lee \& Podsakoff, 2003). A method which can be suggested in order to address this limitation is qualitative interviews in addition to quantitative surveys as a mixed method design.

\section{Conclusion}

The current study provided evidence for the validity of a WIS within the banking industry of South Africa. The scale was confirmed to be a three-factor structure based on the three sources of workplace incivility (supervisor, colleague and instigated). The scale also presented discriminant validity from workplace bullying. In terms of predictive validity, significant negative relationships were found from workplace incivility to work engagement, organisational commitment and job satisfaction, with a positive relationship to turnover intention. Therefore, it is clear that management should refrain from neglecting workplace incivility, as it can have impact on individual and organisational outcomes.

\section{Acknowledgements Competing interests}

The authors declare that they have no financial or personal relationships, which may have inappropriately influenced them in writing this article.

\section{Authors' contributions}

This publication is based on the master's dissertation of O.S. (North-West University). L.D.B. (North-West University) was the study leader of the project, the corresponding author and performed the statistical analyses. The first and second authors contributed equally to the publication version. L.B. (North-West University) was the co-supervisor of the dissertation. M.P.L. (Acadia University) acted as expert reviewer and provided important conceptual input on the manuscript.

\section{References}

Allen, N.J., \& Meyer, J.P. (1990). The measurement and antecedents of affective, continuance and normative commitment to the organization. Journal of Occupational and Organizational Psychology, 63(1), 1-18.

Andersson, L.M., \& Pearson, C.M. (1999). Tit for tat? the spiralling effect of incivility in the workplace. Academy of Management Review, 24(3), 452-471.

Ayeni, C.O., \& Popoola, S.O. (2007). Work motivation, job satisfaction, and organisational commitment of library personnel in academic and research libraries in Oyo State, Nigeria. Library Philosophy and Practice. Retrieved from http://www.webpages. uidaho.edu/ mbolin/tella2.pdf

Bagraim, J.J. (2003). The dimensionality of professional commitment. South Africa Journal of Industrial Psychology, 29(2), 6-9.

Bakker, A.B., \& Demerouti, E. (2007). The Job Demands-Resources Model: State of the art. Journal of Managerial Psychology, 22(3), 309-328. http://dx.doi.org/ 10.1108/02683940710733115

Barling, J., \& Phillips, M. (1993). Interactional, formal, and distributive justice in the workplace: An exploratory study. Journal of Psychology, 127(6), 649-656.

Bartlett, J.E., Bartlett, M.E., \& Reio, T.G. (2008). Workplace incivility: Worker and organizational antecedents and outcomes. Retrieved from http://files.eric.ed. gov/fulltext/ED501638.pdf

Beattie, L., \& Griffin, B. (2014). Day-level fluctuations in stress and engagement in response to workplace incivility: A diary study. Work and Stress, 28(2), 124-142. http://dx.doi.org/10.1080/02678373.2014.898712 
Bibi, Z., Karim, J., \& Din, S. (2013). Workplace incivility and counterproductive work behavior: Moderating role of emotional intelligence. Pakistan Journal of

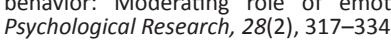

Blau, G., \& Andersson, L. (2005). Testing a measure of instigated workplace civility. Journal of Occupational and Organizational Psychology, 78, 595-614. http://dx. doi.org/10.1348/096317905X26822

Bollen, K.A., Harden, J.J., Ray, S., \& Zavisca, J. (2014). BIC and alternative Bayesian information criteria in the selection of structural equation models. Structural Equation Modeling: A Multidisciplinary Journal, 21(1), 1-19.

Branch, S. (2008). You say tomatoe and I say tomato: Can we differentiate between workplace bullying and other counterproductive behaviours? International Journal of Organisational Behaviour, 13(2), 4-17.

Brown, T.A. (2015). Confirmatory factor analysis for applied research. New York: The Guilford Press.

Chen, Y., Ferris, D.L., Kwan, H.K., Yan, M., Zhou, M., \& Hong, Y. (2013). Self-love's los labour: A self-enhancement model of workplace incivility. Academy of Management Journal, 56(4), 1199-1219. http://dx.doi.org/10.5465/amj.2010.0906

Chidyamakono, N. (2010). Talent retention among trainers and learners in a mining environment Unpublished master's dissertation, North-West University, Potchefstroom, South Africa.

Cingöz, A., \& Kaplan, A. (2015, April). The effect of workplace incivility on job satisfaction and organizational trust: A study of industrial enterprises in turkey. Paper presented in The 2015 WEI International Academic Conference Proceedings, Vienna, Austria, pp. 12-15.

Cohen, J. (1992). Statistical power analysis for the behavioural sciences (Rev. edn.) Orlando, FL: Academic Press.

Cortina, L.M., Magley, V.J., Williams, J.H., \& Langhout, R.D. (2001). Incivility in the workplace: Incidence and impact. Journal of Occupational Health Psychology, 6(1), 64-80.

Cowie, H., Naylor, P., Rivers, I., Smith, P.K., \& Pereira, B. (2002). Measuring workplace bullying. Aggression and Violent Behavior, 7(1), 33-51.

Demerouti, E., Bakker, A.B., Nachreiner, F., \& Schaufeli, W.B. (2001). The job demandsresources model of burnout. Journal of Applied Psychology, 86(3), 499-512. http://dx.doi.org/10.1037/0021- 9010.86.3.499

Dowden, C. (2015). Civility report: Civility matters: An evidence-based review on how to cultivate a respectful federal public service. Association of Professional Executives of the Public Service of Canada.

Duffy, M.K., \& Ferrier, W.J. (2003). Birds of a feather? How supervisor-subordinate dissimilarity moderates the influence of supervisor behaviors on workplace attitudes. Group and Organization Management, 28(2), 217-248.

Du Plooy, G.M. (2002). Communication research: Techniques, methods and applications. (2nd edn.). Cape Town, South Africa: Juta.

Einarsen, S. (2000). Harassment and bullying at work: A Scandinavian approach Aggressive and Violent Behavior: A Review Journal, 5(4), 371-401.

Einarsen, S., \& Skogstad, A. (1996). Bullying at work: Epidemiological findings in public and private organizations. European Journal of Work and Organizational Psychology, 5(2), 185-201.

Estes, B., \& Wang, J. (2008). Workplace incivility: Impacts on individual and organizational performance. Human Resource Development Review. http://dx. doi.org/10.1177/1534484308315565

Foxcroft, C., \& Roodt, G. (2009). Introducing psychological assessment: In the South African context. Cape Town, South Africa: Oxford University Press.

George, D., \& Mallery, P. (2010). SPSS for Windows step by step. A simple guide and reference. (4th edn.). Boston, MA: Allyn and Bacon.

Giorgi, G. (2008). The Negative Acts Questionnaire revised (NAQ-r) in Italy. Prevention Today, 4(4), 71-86.

Glendinning, P.M. (2001). Workplace bullying: Curing the cancer of the American workplace. Public Personnel Management, 30(3), 269-286.

Hellgren, J., Sjöberg, A., \& Sverke, M. (1997). Intention to quit: Effects of job satisfaction and job perceptions. In F. Avallone, J. Arnold, \& K. de Witte (Eds.) Feelings work in Europe (pp. 415-423). Milano, Italy: Guerini.

Hershcovis, M.S. (2010). "Incivility, social undermining, bullying oh my!": A call to reconcile constructs within workplace aggression research. Journal of Organizational Behavior, 32(3), 499-519. http://dx.doi.org/10.1002/job.689

Holm, K. (2014). Workplace incivility as a social process: How witnessing incivility relates to uncivil conduct, well-being, job satisfaction and stress. Unpublished master's thesis, Lund University, Lund, Sweden.

Keenan, A., \& Newton, T.J. (1985). Stressful events, stressors, and psychological strains in young professional engineers. Journal of Occupational Behavior, 6(2) 151-156.

Laschinger, H.K.S., Leiter, M., Day, A., \& Gilin, D. (2009). Workplace empowerment, incivility, and burnout: Impact on staff nurse recruitment and retention outcomes. Journal of Nursing Management, 17(3), 302-311.

Leiter, M.P. (2012). Analyzing and theorizing the dynamics of the workplace incivility crisis. Amsterdam, The Netherlands: Springer.

Leiter, M.P., Laschinger, H.K.S., Day, A., \& Oore, D.G. (2011). The impact of civility interventions on employee social behaviour, distress, and attitudes. Journal of Applied Psychology, 96(6), 1258-1274.

Lim, S., \& Cortina, L.M. (2005). Interpersonal mistreatment in the workplace: The interface and impact of general incivility and sexual harassment. Journal of Applied Psychology, 90(3), 483-496.
Lim, S., Cortina, L.M., \& Magley, V.J. (2008). Personal and workgroup incivility: Impact on work and health outcomes. Journal of Applied Psychology, 93(1), 95-107. on work and health outcomes. Journal of App
$\mathrm{http}: / / \mathrm{dx}$.doi.org/10.1037/0021-9010.93.1.95

Mathis, R.L., \& Jackson, J.H. (2000). Human resource management. (9th edn.). Cincinnati, $\mathrm{OH}$ : South Western College Publishing.

Meyer, J., \& Allen, N. (1991). A three-component conceptualization of organizational commitment. Human Resource Management Review, 1(1), 61-89.

Muthén, L.K., \& Muthén, B.O. (2015). Mplus user's guide. (7th edn.). Los Angeles, CA: Muthén \& Muthén.

Namie, G. (2003). Workplace bullying: Escalated incivility. Ivey Business Journal, 68(2), 1-6.

Nunnally, J.C., \& Bernstein, I.H. (1994). Psychometric theory. (3rd edn.). New York: McGraw-Hill.

Pearson, C.M., \& Porath, C.L. (2005). On the nature of consequences, and remedies of workplace incivility: No time for "nice"? Think again. Academy of Management Executive, 19(1), 7-25.

Pienaar, J., Sieberhagen, C.F., \& Mostert, K. (2007). Investigating turnover intentions by role overload, job satisfaction and social support moderation. South Africa Journal of Industrial Psychology, 33(2), 62-67.

Podsakoff, P.M., MacKenzie, S.B., Lee, J.Y., \& Podsakoff, N.P. (2003). Common method biases in behavioural research: A critical review of the literature and recommended remedies. Journal of Applied Psychology, 88(5), 879-903.

Price, J. (1977). The study of turnover. Ames, lowa: lowa State Press.

Rhoades, L., Eisenberger, R., \& Armeli, S. (2001). Affective commitment to the organization: The contribution of perceived organizational support. Journal of Applied Psychology, 86(5), 825-836.

Rothmann, J.C., \& Rothmann, S. (2006). The South African employee health and wellness survey: User manual. Potchefstroom, South Africa: Afriforte (Pty) Ltd.

Salin, D. (2003). Ways of explaining workplace bullying: A review of enabling, motivating and precipitating structures and processes in the work environment. Human Relations, 56(10), 1213-1232.

Schaufeli, W., \& Bakker, A.B. (2003). Utrecht work engagement scale: Preliminary manual. Utrecht University, The Netherlands: Occupational Health Psychology Unit.

Schaufeli, W.B., Bakker, A.B., \& Salanova, M. (2006). The measurement of work engagement with a short questionnaire: A cross-national study. Educational and Psychological Measurement, 66(4), 701-716.

Shim, J. (2015). Concept exploration of workplace incivility: Its implication to HRD. Unpublished master's dissertation, University of Minnesota, Minneapolis, MN.

Shim, J., \& Chang, H. (2012, August). The relationship between workplace incivility and the intention to leave: Implication to HRD. Paper presented at the Krivet Conference, Asia, South Korea.

Sjöberg, A., \& Sverke, M. (2000). The interactive effect of job involvement and organizational commitment on job turnover revisited: A note on the mediating role of turnover intention. Scandinavian Journal of Psychology, 41(3), 247-252.

Spector, P.E. (1994). Using self-report questionnaires in OB research: A comment on the use of a controversial method. Journal of Organizational Behaviour, 15(5), 385-392.

Steers, R.M. (1977). Antecedents and outcomes of organizational commitment. Administrative Science Quarterly, 22(1), 46-56.

Storm, K., \& Rothmann, S. (2003). A psychometric analysis of the Utrecht Work Engagement Scale in the South African Police Service. South Africa Journal of Industrial Psychology, 29(4), 62-70.

Struwig, F.W., \& Stead, G.B. (2001). Planning, designing and reporting research. Cape Town, South Africa: Pearson Education.

Suleal, C., Fischmann, G., \& Filipescu, R. (2012). Conscientious, therefore engaged in work? Don't take it for granted: The moderating role of workplace mistreatment. Human Resources Psychology, 10(2), 23-32.

Taris, T.W., \& Kompier, M.A.J. (2006). Games researchers play: Extreme-groups analysis and mediation analysis in longitudinal, occupational, and health research. Scandinavian Journal of Work, Environment, and Health, 32(6), 463-472.

Tarraf, R.C. (2012). Taking a closer look at workplace incivility: Dimensionality and source effects. Unpublished master's thesis, The University of Western Ontario, Ontario, Canada.

Taylor, S.G. (2010). Cold looks and hot tempers: Individual-level effects of incivility in the workplace. Unpublished doctoral thesis, Bradley University, Peoria, IL.

Teddie, C., \& Yu, F. (2007). Mixed methods sampling: A typology with examples. Journal of Mixed Methods Research, 1(1), 77-100. http://dx.doi.org/10.1177/ 2345678906292430

Uzondu, C.N., Kelechi, A., Emmanuel, A.E., \& Ebere, O. (2014). Influence of supervisor's incivility, perceived organizational justice and gender on organizational commitment. International Journal of Information Research and Review, 1(11), 165-172.

Van de Mortel, T.F. (2008). Faking it: Social desirability response bias in self-report research. Australian Journal of Advanced Nursing, 25(4), 40-48.

Van de Schoot, R., Lugtig, P., \& Hox, J. (2012). A checklist for testing measurement invariance. European Journal of Developmental Psychology, 9(4), 486-492. http:// dx.doi.org/10.1080/17405629.2012.686740

Van den Broeck, A.D., Baillien, E., \& Witte, H.D. (2011). Workplace bullying: A perspective from the Job Demands-Resources model. South Africa Journal of Industrial Psychology, 37(2), 40-51.

Welsh, B.C., Braga, A.A., \& Bruinsma, G.J. (2015). Reimagining broken windows from theory to policy. Journal of Research in Crime and Delinquency, 52(4), 447-463. 